\title{
Desenvolvimento de projetos educacionais por futuros docentes de computação por meio de um Ava Offline
}

Development of educational practices by future computer teachers through Offline

Robert Mady Nunes (iD https://orcid.org/0000-0002-1101-9335

Instituto Federal de Educação, Ciência e Tecnologia do Tocantins

e-mail-robert.nunes@ifto.edu.br

Miriam Ines Marchi (iD https://orcid.org/0000-0003-2546-7072

Universidade do Vale do Taquari - Univates

e-mail -mimarchi@univates.br

\section{Resumo}

A falta de acesso e o elevado custo de infraestrutura para o uso de tecnologias digitais, em instituições na zona rural do Brasil, dificulta a adoção de novas metodologias e práticas pedagógicas por parte de professores. Assim, este estudo tem como objetivo investigar a utilização de um Ambiente Virtual de Aprendizagem (AVA), sem comunicação com a Internet, como o principal meio de interação para o planejamento de novas práticas pedagógicas por futuros docentes de computação. Foi feita uma intervenção pedagógica, realizada durante 10 encontros, com 17 alunos da disciplina Tecnologias de Ensino a Distância, do $3^{\circ}$ período do curso de Licenciatura em Computação do Instituto Federal de Educação, Ciência e Tecnologia do Tocantins - campus Dianópolis. Para tanto, utilizou-se um ambiente virtual, na plataforma Moodle, para ser o espaço de convergência onde os aportes teóricos e ferramentas digitais estariam disponíveis aos licenciandos em computação. Já os métodos utilizados para a coleta dos dados da pesquisa foram a observação e a análise das produções. Diante desse cenário, foi possível identificar as principais vantagens e desvantagens do uso das tecnologias digitais utilizadas e os desafios que os alunos tiveram no decorrer da intervenção pedagógica. Além disso, percebeu-se a evolução dos futuros professores de computação por meio da construção dos seus projetos educacionais, que alinharam assuntos de áreas curriculares distintas com tecnologias digitais, como GeoGebra, Simuladores do PhET, wiki e Fritzing, além de um jogo digital.

Palavras-chave: Ambiente Virtual. Formação de professores. Projetos educacionais.

\section{Abstract}

The shortage of access and the high cost of infrastructure for the use of digital technologies in educational institutions based in a rural area, in Brazil, hamper the 
adoption of new methodologies and pedagogical practices by teachers. Therefore, this study aims to investigate the use of a Virtual Learning Environment (VLE), without any communication with the Internet, as the primary means of interaction for planning new pedagogical practices by future computer teachers. A pedagogical intervention was carried out in the Distance Learning Technologies subject, with 17 undergraduate students, from the $3^{\text {rd }}$ academic semester of the Computing Degree course offered at the Tocantins Federal Institute of Education, Science, and Technology - university campus of Dianópolis. For this purpose, a virtual classroom was used on the Moodle platform to be the convergence room where theoretical contributions and digital tools would be available to computing undergraduate students. The methods used for the data collection were observation and analysis of productions. Based on this scenario, it was possible to identify the main advantages and disadvantages of using digital technologies and the challenges that computing undergraduate students had in the course of the pedagogical intervention. Furthermore, the development of future computer teachers was noticed through the construction of their educational practices which aligned subjects from different areas with digital technologies, such as GeoGebra, PhET Simulators, wiki, and Fritzing, in addition to a digital game.

Keywords: Virtual Classroom. Teacher Education. Educational Practices.

\section{Introdução}

A formação inicial de professores necessita possibilitar a preparação de profissionais capazes de organizar meios para a aprendizagem. Tal medida se deve ao fato dos novos desafios que o sistema educacional vivencia, em que é necessário que o professor evolua para acompanhar a nova realidade que se apresenta (PERRENAUD et al., 2008). Para Ponte (2002), a tendência atual, em que os futuros docentes serão inseridos, proporciona o acesso à informação de forma otimizada, por meio do uso das tecnologias digitais. Com isso, também é possível viabilizar a modificação e a produção de novas informações.

Via de regra, os cursos de formação inicial de professores são responsáveis pela qualificação adequada dos indivíduos no que se refere à utilização das tecnologias digitais voltadas para a educação (LIMA, 2001). Assim sendo, é necessário viabilizar aos futuros professores meios para a compreensão de como integrar as tecnologias digitais às práticas pedagógicas (MENEZES, 2014).

Nesse sentido, Reis e Mendes (2018, p. 314) ressaltam que a principal motivação que leva os atuais docentes a planejarem novas práticas pedagógicas, que envolvam o uso de tecnologias digitais, está diretamente relacionada "à aproximação que eles tiveram com a área na licenciatura e um aprofundamento na temática via curso extracurricular, formação continuada e pós-graduação". Com isso, Valente (2005) defende que, na formação do professor, devem-se criar condições para que o indivíduo construa o conhecimento referente ao uso de tecnologias digitais, incentivando a compreensão de como relacionar as perspectivas educacionais com tais tecnologias e de como integrá-las à prática pedagógica.

Todavia, instituições de ensino que se localizam em zonas rurais tendem a ser 
prejudicadas quando a questão se refere à disponibilidade de recursos tecnológicos para auxiliar os processos de ensino, principalmente em relação à conectividade com a Internet. A dificuldade de acesso e o elevado custo para dispor uma infraestrutura adequada para o uso de tecnologias digitais, em instituições na zona rural, contribui negativamente para a adoção de novas metodologias e práticas pedagógicas por parte dos professores.

Nesse contexto, o curso de Licenciatura em Computação do Instituto Federal de Educação, Ciência e Tecnologia do Tocantins (IFTO) vivenciou o problema de falta de infraestrutura para viabilizar o uso de tecnologias digitais voltadas para o ensino, uma vez que é um campus rural localizado nas proximidades do município de Dianópolis, no sudeste do Estado do Tocantins. Com isso, suscitou-se a problemática: É possível que um Ambiente Virtual de Aprendizagem, sem comunicação com a Internet, possa se tornar o principal meio de interação para o planejamento de novas práticas pedagógicas por futuros docentes de computação?

Diante desse cenário, teve-se a ideia de implantar um Ambiente Virtual de Aprendizagem, na plataforma Moodle, para ser acessado localmente na rede do supracitado campus. Assim, a partir do uso de tal AVA, foi realizada uma intervenção pedagógica composta por 10 encontros, em que os alunos tiveram acesso a produções e ferramentas digitais focadas no desenvolvimento dos processos de ensino.

Com o auxílio da estrutura montada no AVA Moodle, proporcionou-se a 17 alunos da disciplina Tecnologias de Ensino a Distância do $3^{\circ}$ período, um ambiente propício para o desenvolvimento de projetos educacionais, os quais, neste trabalho, se referem ao planejamento de práticas pedagógicas envolvendo ferramentas digitais centradas no ensino. Dessa forma, foram integradas ao Ambiente Virtual de Aprendizagem, além dos recursos nativos, ferramentas que possibilitaram a construção do conhecimento e que não necessitavam de interação com a Internet.

Assim sendo, este trabalho também objetivou a compreensão de algumas hipóteses relacionadas à supracitada problemática, tais como: os licenciandos em computação possuem conhecimento satisfatório em relação ao uso de recursos tecnológicos digitais voltados para o ensino; e pode-se utilizar um AVA que seja acessado de forma local no campus do IFTO, para que os estudantes utilizem-no como espaço central de práticas didáticas.

\section{O uso de tecnologias digitais para a construção de novas metodologias de ensino}

As tecnologias digitais são recursos que viabilizam a integração, a instantaneidade, a comunicação e a interatividade (MORAN, 2013). Nesse sentido, Prensky (2001) acredita que os atuais professores necessitam adaptar suas metodologias e práticas educacionais à linguagem dos seus alunos, por meio da utilização de ferramentas que tragam interesse e motivação à sala de aula. Dessa maneira, o professor otimiza seu tempo, antes gasto para repassar informações, para fomentar atividades mais criativas e estimulantes para os alunos:

As tecnologias digitais facilitam a pesquisa, a comunicação e divulgação em rede. Temos as tecnologias mais organizadas, como os ambientes virtuais de aprendizagem - a exemplo do Moodle e semelhantes --, que permitem que tenhamos certo controle de quem acessa o ambiente e do 
que é preciso fazer em cada etapa de cada curso. Além desses ambientes mais formais, há um conjunto de tecnologias, que denominamos popularmente de 2.0, mais abertas, fáceis e gratuitas (blogs, podcast, wikis etc.), em que os alunos podem ser protagonistas de seus processos de aprendizagem, e que facilitam a aprendizagem horizontal, isto é, dos alunos em si, das pessoas em redes de interesse etc. (MORAN; MASETTO; BEHRENS, 2015, p. 31).

Kenski (2013) defende que os Ambientes Virtuais de Aprendizagem (AVAs) podem ser considerados espaços de convergência, ao possibilitar a aprendizagem de pessoas sobre determinados assuntos por meio de uma diversidade de recursos digitais, proporcionando o uso de vários formatos de arquivos, como: texto, imagens e áudios. Além disso, os AVAs da atualidade possibilitam aprendizagens lúdicas, por meio de desafios e jogos, o que possibilita a colaboração entre os indivíduos e fomenta a inserção de novos valores, atitudes e habilidades (MUNHOZ, 2013; KENSKI, 2013). Nesse sentido, para a implantação de um AVA deve-se levar em consideração o conhecimento e objetivos a serem alcançados pelo público a que se destina. Almeida (2003) reforça que os AVAs têm por finalidade a construção de atividades educacionais por meio de ferramentas digitais, nas quais é possível a integração com múltiplas mídias, linguagens e recursos, proporcionando, assim, as interações entre pessoas e objetos de aprendizagem.

Nesse contexto, pode-se dizer que o uso das tecnologias digitais voltadas para o cenário do ensino possibilita aos docentes a construção de novas metodologias de ensino, assim como novas práticas pedagógicas. Tal ideia é reforçada por Almeida (2005, p.40), a qual defende que:

\begin{abstract}
A utilização de tecnologias na escola e na sala de aula impulsiona a abertura desses espaços ao mundo e ao contexto, permite articular as situações global e local, sem, contudo, abandonar o universo de conhecimentos acumulados ao longo do desenvolvimento da humanidade. Tecnologias e conhecimentos integram-se para produzir novos conhecimentos que permitam compreender as problemáticas atuais e desenvolver projetos, em busca de alternativas para a transformação do cotidiano e a construção da cidadania.
\end{abstract}

Para Almeida (2005), ao adotar a metodologia de construção de projetos com auxílio de tecnologias digitais, o professor deve levar em consideração o cotidiano do aluno. Dessa maneira, o conteúdo a ser abordado deve ser de conhecimento do estudante, para que o estimule no desenvolvimento do conhecimento científico, o que também irá ajudá-lo na compreensão de mundo. Com isso, unindo a investigação e a organização das informações com as tecnologias digitais, possibilita-se a criação de novas formas de representar o conhecimento.

Assim sendo, este trabalho faz referência à expressão Projetos Educacionais no que tange ao planejamento de novas práticas pedagógicas que envolvam tecnologias digitais voltadas para o ensino.

\title{
Procedimentos para o desenvolvimento do trabalho
}

Para o desenvolvimento das ações do presente trabalho, como supracitado, foi implantado um AVA, na plataforma Moodle, de forma que fosse acessado em rede local no campus rural de Dianópolis (TO). Dessa maneira, o ambiente foi utilizado pelos futuros docentes em computação, da disciplina de Tecnologias de Ensino a Distância, sem que houvesse a comunicação com a Internet. 
Nesse cenário, definiu-se o AVA Moodle como o espaço de convergência responsável pelo desenvolvimento dos projetos educacionais. Sendo assim, no AVA foi organizado um curso, chamado Tecnologias de Ensino a Distância, no qual os alunos teriam acesso às produções de Teixeira e Strohschoen (2015), Padilha e Branchier (2016), Quartieri, Neves e Weimer (2016) que fazem referência a práticas pedagógicas com o auxílio de tecnologias digitais. Para tanto, as produções fizeram uso das ferramentas digitais wiki, GeoGebra e simulador do PhET, respectivamente. Em paralelo a isso, foram criados cursos onde os licenciandos, organizados em grupos, possuiriam privilégios de docentes, para que pudessem reproduzir as citadas produções e desenvolvessem seus projetos educacionais, assim como mostra a Figura 1.

Figura 1 - Estrutura dos cursos do AVA disponibilizados aos licenciandos em computação

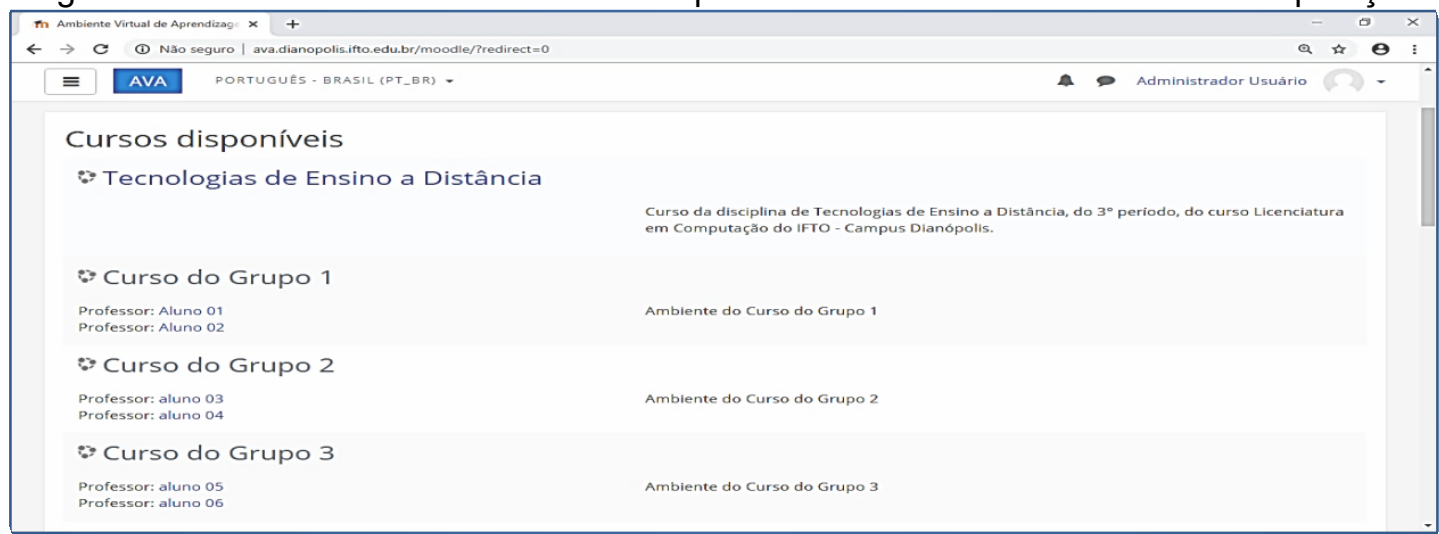

Fonte: Elaboração própria (2020), a partir da plataforma Moodle.

Já as ações da presente intervenção pedagógica foram organizadas em 10 encontros presenciais, com carga horária de 2 horas por encontro, totalizando uma carga horária de 20 horas, como apresenta o Quadro 1.

Quadro 1 - Organização dos encontros da intervenção pedagógica

\begin{tabular}{|c|l|l|}
\hline Encontro & \multicolumn{1}{|c|}{ Objetivos } & \multicolumn{1}{c|}{ Metodologia } \\
\hline 1 & $\begin{array}{l}\text { Esclarecer aos alunos o funcionamento } \\
\text { dos processos da intervenção } \\
\text { pedagógica realizada durante os } 10 \\
\text { encontros. }\end{array}$ & $\begin{array}{l}\text { Aula expositiva e dialogada } \\
\text { com o uso de slides para } \\
\text { apresentar a proposta. }\end{array}$ \\
\hline \multirow{5}{*}{2} & $\begin{array}{l}\text { Apresentar os principais conceitos } \\
\text { referentes a Ambientes Virtuais de } \\
\text { Aprendizagem; } \\
\text { Apresentar o AVA Moodle implantado no } \\
\text { campus de Dianópolis e explorar suas } \\
\text { funcionalidades internas. }\end{array}$ & $\begin{array}{l}\text { Aula expositiva e dialogada } \\
\text { com o uso de slides para } \\
\text { apresentar os conceitos de } \\
\text { AVA. } \\
\text { Utilização do AVA Moodle } \\
\text { para a exploração de } \\
\text { ferramentas. }\end{array}$ \\
\hline \multirow{5}{*}{3} & $\begin{array}{l}\text { Demonstrar o uso da ferramenta wiki } \\
\text { para o ensino de genética; } \\
\text { Explorar os recursos disponíveis no AVA } \\
\text { Moodle para construir atividades com } \\
\text { wiki, fórum e chat, objetivando } \\
\text { demonstrar, aos licenciandos, o uso de } \\
\text { recursos colaborativos para a criação de } \\
\text { um projeto educacional. }\end{array}$ & $\begin{array}{l}\text { Uara a exploração de } \\
\text { ferramentas colaborativas. }\end{array}$ \\
\hline \multirow{2}{*}{4} & $\begin{array}{l}\text { Exemplificar o desenvolvimento de } \\
\text { atividades educacionais, referentes à }\end{array}$ & $\begin{array}{l}\text { Utilização do AVA Moodle } \\
\text { para a exploração de }\end{array}$ \\
\hline
\end{tabular}




\begin{tabular}{|c|l|l|}
\hline & $\begin{array}{l}\text { trigonometria, utilizando o Software } \\
\text { GeoGebra; } \\
\text { Demonstrar como integrar o GeoGebra } \\
\text { ao AVA Moodle. }\end{array}$ & $\begin{array}{l}\text { integração e manipulação } \\
\text { do GeoGebra. }\end{array}$ \\
\hline 5 & $\begin{array}{l}\text { Exemplificar o desenvolvimento de } \\
\text { atividades educacionais referentes à } \\
\text { energia, energia potencial e cinética, } \\
\text { utilizando simulador do PhET; } \\
\text { Demonstrar como integrar os } \\
\text { simuladores do PhET ao AVA Moodle. }\end{array}$ & $\begin{array}{l}\text { Utilização do AVA Moodle } \\
\text { para a exploração de } \\
\text { integração e manipulação } \\
\text { de simulador do PhET. }\end{array}$ \\
\hline 6 & $\begin{array}{l}\text { Explorar as possibilidades dos } \\
\text { questionários em formato de Quiz que } \\
\text { podem ser utilizados no AVA Moodle; } \\
\text { Demonstrar como integrar o StudentQuiz } \\
\text { ao AVA Moodle. }\end{array}$ & $\begin{array}{l}\text { Utilização do AVA Moodle } \\
\text { para a exploração de } \\
\text { integração e manipulação } \\
\text { do StudentQuiz. }\end{array}$ \\
\hline 7 & $\begin{array}{l}\text { Definir a ferramenta a ser utilizada e o } \\
\text { tema do projeto educacional; } \\
\text { Disponibilizar um documento modelo } \\
\text { para auxiliar na construção do } \\
\text { documento do projeto educacional. }\end{array}$ & $\begin{array}{l}\text { Debates entre os grupos de } \\
\text { alunos. }\end{array}$ \\
\hline 8 e 9 & $\begin{array}{l}\text { Construir os projetos educacionais no } \\
\text { AVA Moodle, utilizando a ferramenta } \\
\text { escolhida. }\end{array}$ & $\begin{array}{l}\text { Utilização do AVA Moodle } \\
\text { para a construção de } \\
\text { projetos educacionais. }\end{array}$ \\
\hline 10 & $\begin{array}{l}\text { Apresentação dos projetos educacionais } \\
\text { pelos alunos. }\end{array}$ & $\begin{array}{l}\text { Utilização do AVA Moodle } \\
\text { para a exposição de } \\
\text { projetos educacionais. }\end{array}$ \\
\hline
\end{tabular}

Fonte: Elaboração própria (2020).

Desse modo, além das metodologias vistas no Quadro 1, reforça-se que uma das práticas adotadas foi a utilização do ensino por meio de projetos. Para tanto, nos 6 primeiros encontros foram trabalhadas as propostas de Teixeira e Strohschoen (2015), Padilha e Branchier (2016) e Quartieri, Neves e Weimer (2016) para que servissem de referência de como se construir um projeto. Já nos 4 encontros finais, os alunos ficaram responsáveis por desenvolverem seus próprios projetos de ensino.

Por fim, para o desenvolvimento da interversão pedagógica, o IFTO disponibilizou um laboratório de informática com um projetor e 30 computadores interligados em rede local. Já em relação à caracterização da turma escolhida, como citado anteriormente, o grupo foi constituído por 17 alunos, entre jovens e adultos com faixa etária entre 18 e 40 anos. Para tanto, neste trabalho, tais alunos foram nomeados com os pseudônimos Aluno01 a Aluno17 e tiveram suas falas destacadas com o recuo de $4 \mathrm{~cm}$, com tamanho 10 e espaço simples.

\section{Características da pesquisa, métodos de coleta e análise dos dados}

O trabalho apresentou procedimentos pautados na pesquisa qualitativa, a qual, para Stake (2011), é conhecida pela descrição de ações pessoais e ambientes complexos, além da integridade do pensamento. Desse modo, necessitou-se utilizar instrumentos que possibilitassem a coleta de dados subjetivos, o que resultou no uso dos métodos de observações, com auxílio de um diário de campo e análise de 
produções.

Características de estudo de caso também são encontradas na presente pesquisa. Para tanto, Lüdke e André (2013) argumentam que o estudo de caso tem conquistado espaço na área da educação, pelo potencial que apresenta diante do estudo de questões sobre instituições de ensino.

Por se tratar de uma pesquisa que abordou os métodos de observação e interpretação das produções dos licenciandos em computação, o trabalho adotou a análise descritiva para os dados coletados. Dessa forma, com base nos conceitos da análise descritiva, os dados foram tratados de forma organizada com a finalidade de proporcionar resultados confiáveis e fiéis.

\section{Resultados e discussões}

A presente seção descreve, de forma detalhada, cada encontro da intervenção pedagógica realizada. Assim, são descritos a forma de utilização do AVA Moodle proposto, bem como os procedimentos e projetos educacionais realizados pelos futuros professores de computação.

Diante disso, o encontro 1 teve por finalidade apresentar a proposta da intervenção pedagógica aos alunos da disciplina de Tecnologia de Ensino a Distância. Para tanto, foram detalhadas a motivação, a problemática e os objetivos utilizados para o desenvolvimento do estudo. Ressalta-se que foi enfatizado que durante os encontros os participantes fariam uso de tecnologias digitais voltadas para o ensino, por meio de um Ambiente Virtual de Aprendizagem sem interação com a Internet. Assim, os projetos educacionais ali desenvolvidos poderiam se tornar fontes de pesquisas mais elaboradas, como trabalhos para os estágios em docência e trabalhos de conclusão de curso.

Já o segundo encontro foi marcado por uma aula expositiva e dialogada sobre os principais conceitos de Ambientes Virtuais de Aprendizagem, bem como os conceitos sobre a plataforma Moodle. Os conceitos abordados foram: o propósito dos AVAs e suas potencialidades para a docência; conceitos sobre o AVA Moodle e as possibilidades oferecidas por ele; contexto mundial, nacional e estadual da utilização do AVA Moodle; e possibilidades do desenvolvimento de projetos educacionais por meio do AVA Moodle.

Foi também no encontro 2 que ocorreu a organização dos licenciandos em grupos para que fosse possível dar continuidade à intervenção com a estruturação dos cursos no ambiente virtual. Após isso, foi apresentado aos estudantes o AVA Moodle, implantado na rede local do campus Dianópolis. Nesse sentido, durante a exploração do AVA pelos licenciandos em computação, foi informado que todo o acesso realizado ocorria sem a necessidade de conectividade com a Internet. Diante dessa informação, os alunos se mostraram surpresos e externaram comentários como:

Aluno11 - Nossa! Não precisa de nenhum tipo de conexão com a Internet. Aluno08 - O acesso é rápido!

Com isso, percebeu-se, também, que o entusiasmo dos alunos foi motivado por não terem tido contato, anteriormente, com Ambientes Virtuais de Aprendizagem preparados especificamente para suas aulas, ainda mais por um que não possuísse 
interação com a Internet, evidenciando, assim, uma das teorias de Prensky (2001), a qual discorre sobre a necessidade de o docente buscar mudanças na sua metodologia e prática pedagógica, adaptando os materiais à linguagem dos nativos digitais, a fim de alcançar o interesse de seus alunos.

Em continuidade, no encontro 3 foi apresentado o produto educacional desenvolvido por Teixeira e Strohschoen (2015). Assim, foi demonstrado aos licenciandos as possibilidades trazidas pelo uso da ferramenta wiki, utilizada no AVA PBwork, para o ensino de genética em uma turma do $3^{\circ}$ ano do Ensino Médio.

Após a apresentação do citado produto educacional, foram apresentados os recursos colaborativos do AVA Moodle. Dessa maneira, foi solicitado aos estudantes que acessassem seu curso com privilégios de docentes e reproduzissem a construção de uma wiki.

Diante desse cenário, com o desenvolvimento das wikis foi possível perceber o interesse dos alunos no uso da ferramenta para conteúdos de outras disciplinas do curso de Licenciatura em Computação. Tal percepção pode ser evidenciada nas falas de alguns alunos, como:
Aluno08 - Seria bom usar em Eletrônica Básica.
Aluno06 - Poderia aplicar em algo para a disciplina de Redes de Computadores.
Aluno01 - Pensei em fazer daquela matéria do primeiro período, Fundamentos Filosóficos.
Aluno13 - Tem matérias muito interessantes para utilizar, como a Didática,
onde temos que ler muito.

Assim sendo, por meio do método de observação, identificou-se que alguns licenciandos perceberam as potencialidades das ferramentas colaborativas para a construção do conhecimento e como métodos inovadores para avaliar o grau de interação de cada aluno, indo, assim, ao encontro da teoria defendida por Coutinho e Farbiarz (2010), quando argumentam que ambientes colaborativos podem ser eficazes para a construção do conhecimento, uma vez que possibilitam discussões e uma centralização das informações, incentivando a participação e reflexão dos alunos.

$\mathrm{Na}$ sequência, no quarto encontro foi apresentada a produção de Padilha e Branchier (2016) referente à exploração interativa sobre a trigonometria no triângulo retângulo por meio do GeoGebra. Assim, foi realizada a demonstração da contextualização, em que se apresentavam a justificativa e o objetivo do trabalho, o detalhamento da tecnologia digital utilizada, no caso o GeoGebra, e o modo como as questões eram formuladas. A demonstração serviu para nortear os alunos em como construir um projeto educacional.

Como neste encontro foi utilizado o software GeoGebra, necessitou-se preparar tal ferramenta para que fosse acessada de forma offline, dentro do AVA Moodle. Para isso, foi integrada uma versão, em formato de página web, do GeoGebra ao AVA, a qual após configurada não realizava sincronização com a Internet

Posteriormente a isso, foi solicitado aos alunos que realizassem os passos do trabalho de Padilha e Branchier (2016), como mostra a Figura 2, utilizando a versão offline do GeoGebra. Tal solicitação focou na percepção de como uma prática pedagógica que envolva tecnologias digitais necessita ser bem construída e detalhada pelo professor. 
Figura 2 - Executando os passos do trabalho de Padilha e Branchier (2016)

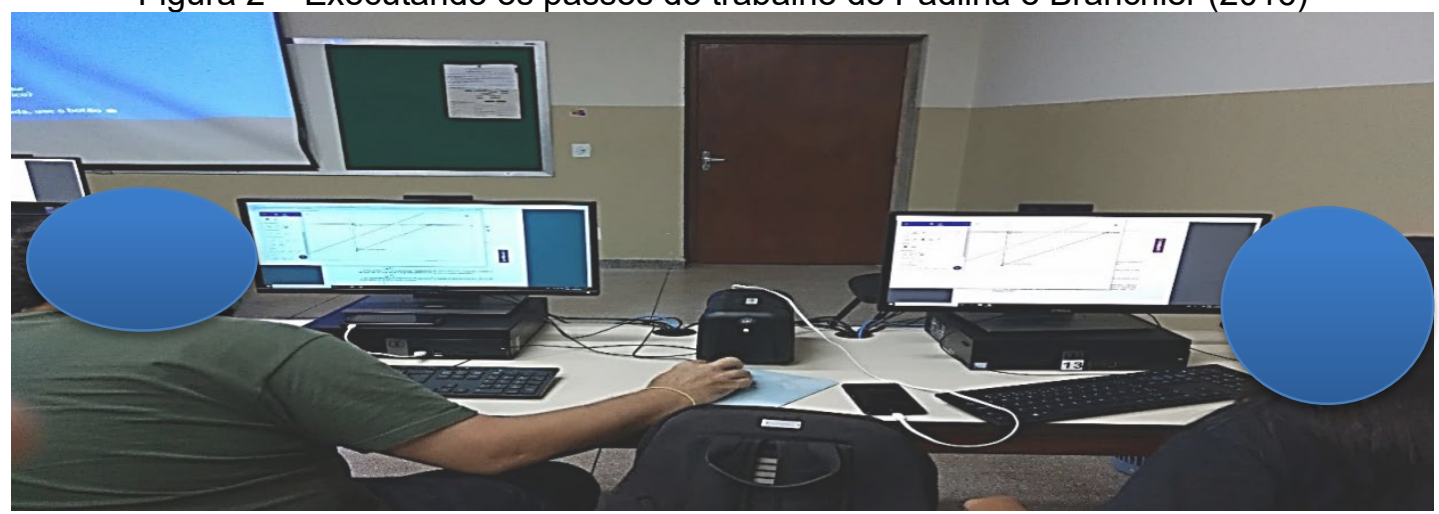

Fonte: Elaboração própria (2020).

Com o desenvolvimento da atividade e por meio do método de observação, foi possível perceber que os alunos se mostravam motivados e empenhados. Como o foco do encontro foi apresentar as potencialidades do GeoGebra para a construção de uma prática pedagógica, também foi solicitado aos licenciandos que, ao invés de tentarem responder os questionários da atividade, fizessem uma análise de como as atividades foram elaboradas. No caso, tal solicitação teve o intuito de fazer com que os licenciandos percebessem como é importante uma boa elaboração de questões, para, assim, de fato, auxiliar a construção do conhecimento.

No encontro 5, foi apresentado aos licenciandos o trabalho de Quartieri, Neves e Weimer (2016), o qual teve a exposição de atividades, utilizando tecnologias digitais elaboradas por professores de matemática e física de um curso de formação continuada. Entretanto, o foco maior se deu na atividade desenvolvida para o ensino dos conteúdos de conservação de energia, energia potencial e cinética que utilizava um simulador de física do PhET. Dessa maneira, após a leitura do texto, foi solicitado aos estudantes que realizassem os passos da atividade proposta.

Como a intenção do encontro 5 foi verificar as potencialidades dos simuladores do PhET, também foi disponibilizado um simulador de eletrônica, como mostra a Figura 3 , que possibilitava a construção de circuitos básicos. Tal procedimento foi motivado pelo fato de os alunos possuírem a disciplina de Eletroeletrônica na estrutura curricular do curso de Licenciatura em Computação. Desse modo, a ideia seria desafiar os licenciandos para a produção de projetos educacionais com o uso de simuladores, para disciplinas que são de conhecimento deles. 
Figura 3 - Manipulando o simulador de eletrônica

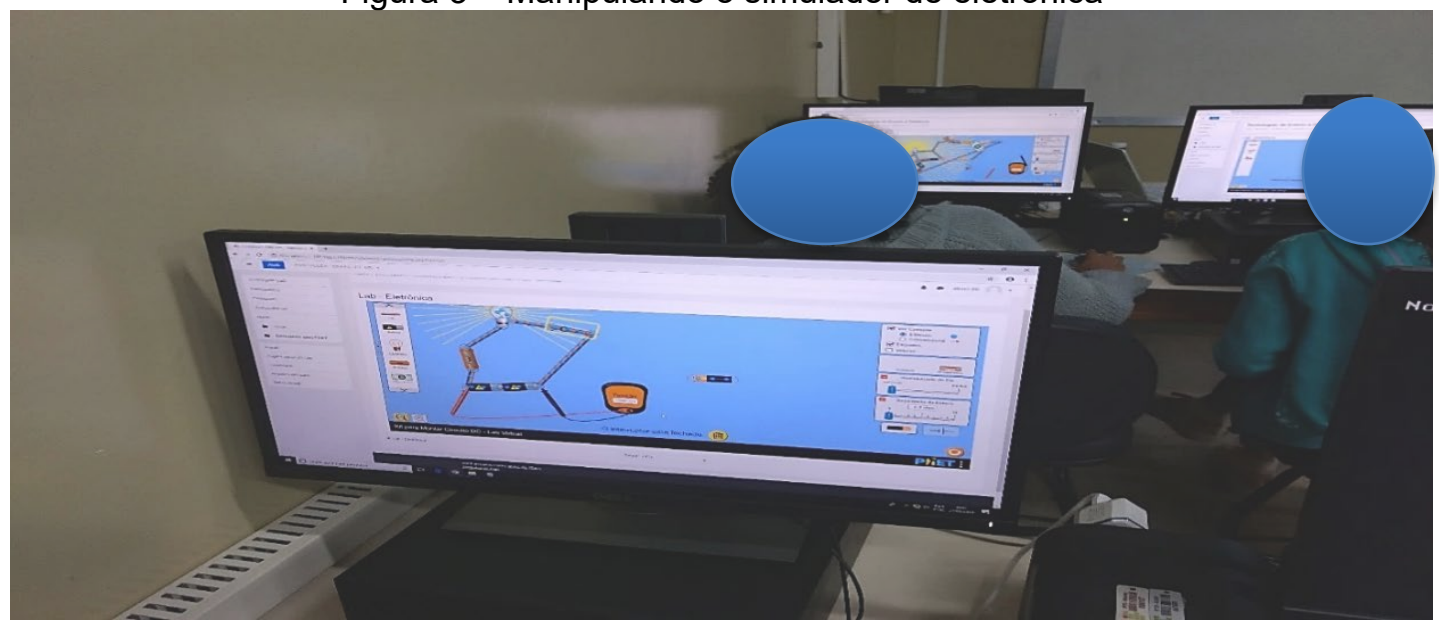

Fonte: Elaboração própria (2020).

Com a manipulação do simulador de eletrônica, os licenciandos explanaram comentários como estes:

Aluno11 - Precisa tomar cuidado para não aumentar muito a voltagem para não pegar fogo no circuito.

Aluno17 - Assim como na aula de eletrônica, é possível realizar os testes com multímetro.

Diante disso, percebeu-se que, mesmo sem a exposição de um trabalho envolvendo conteúdos sobre eletrônica, os alunos foram capazes de manipular as funções disponíveis no simulador. Isso se deve ao fato de que os licenciandos, em boa parte, possuíam conhecimentos do conteúdo abordado pela tecnologia utilizada. Além disso, a associação, pelo Aluno17, evidenciou como uma ferramenta bem desenvolvida pode ser de grande valia para auxiliar no ensino de um conteúdo técnico, podendo até mesmo substituir o laboratório em instituições que não possuem os recursos físicos necessários.

Em continuidade à intervenção pedagógica, o encontro 6 foi destinado à apresentação de questionários no formato de Quiz. Desse modo, foi apresentado um questionário padrão do AVA Moodle e um questionário com elementos de gamificação ${ }^{1}$, chamado StudentQuiz, que poderia adicionalmente ser integrado ao AVA Moodle.

Durante a apresentação, os licenciandos foram solicitados a responderem as questões propostas nos dois questionários, com o intuito de perceberem 0 comportamento de cada ferramenta e suas particularidades. Todavia, as questões disponíveis nos questionários foram referentes a conteúdos de disciplinas da Licenciatura em Computação, como Arquitetura de Computadores e Introdução à Informática, já cursada pelos estudantes.

Nesse cenário, compreendeu-se que os alunos identificaram potencialidades nos elementos de gamificação utilizados em questionários. Desse modo, foi possível perceber, também, que os estudantes vislumbraram as possibilidades de construir o conhecimento por meio de uma nova abordagem, trazendo o entretenimento para dentro da sala de aula. Tais percepções vão ao encontro da teoria de Vianna (2014),

\footnotetext{
1 "Gamificação surge como uma possibilidade de conectar a escola ao universo dos jovens com o foco na aprendizagem, por meio de práticas como sistemas de rankeamento e fornecimento de recompensas" (ALVES; MINHO; DINIZ, 2014, p. 83).
}

4


a qual discorre que utilizar o processo de gamificação não significa, necessariamente, fazer uso de um jogo, mas, sim, de seus aspectos mais importantes, como a estética, a mecânica e a dinâmica com a finalidade de imitar as vantagens que costumam ser almejadas com eles.

No $7^{\circ}$ encontro foi solicitado aos grupos que definissem os temas de seus projetos educacionais, nos quais deveriam levar em consideração o assunto que gostariam de trabalhar e qual tecnologia digital era de sua preferência. Para tal solicitação, não foram impostas limitações ou realizados sorteios, ou seja, os alunos ficaram livres para escolherem tanto o assunto quanto a ferramenta que desejassem.

Isso posto, percebeu-se que os grupos diversificaram em suas escolhas de ferramentas, pois foram citados o uso de wiki, simuladores do PhET, GeoGebra e GeoGebra com StudentQuiz. Além disso, um dos grupos apresentou uma ferramenta similar ao simulador de eletrônica do PhET, chamado Fritzing, que tem por finalidade simular a construção de circuitos elétricos.

No entanto, para nortear os alunos no desenvolvimento dos seus projetos educacionais, foi descrita uma estrutura modelo de trabalho (QUADRO 2), baseada nas produções de Teixeira e Strohschoen (2015), Padilha e Branchier (2016) e Quartieri, Neves e Weimer (2016), apresentadas nos encontros 3, 4 e 5. Essa estrutura serviu para minimizar as dúvidas e funcionar como documento base para o detalhamento dos projetos educacionais.

Quadro 2 - Estrutura modelo dos projetos educacionais

\begin{tabular}{|c|l|}
\hline \multicolumn{1}{|c|}{ Item } & \multicolumn{1}{c|}{ Descrição } \\
\hline $\begin{array}{c}\text { Título do Projeto } \\
\text { Educacional }\end{array}$ & Definir o título para o trabalho desenvolvido. \\
\hline Nomes e e-mails & $\begin{array}{l}\text { Acrescentar os nomes e e-mails de todos os desenvolvedores do } \\
\text { trabalho. }\end{array}$ \\
\hline Contextualização & $\begin{array}{l}\text { Contextualização sobre o assunto que será trabalhado, bem como } \\
\text { sobre a tecnologia digital a ser utilizada. Para tanto, é interessante } \\
\text { que a justificativa do trabalho esteja explícita neste texto. }\end{array}$ \\
\hline Objetivo & $\begin{array}{l}\text { Descrever o objetivo do trabalho, caso não tenha sido deixado } \\
\text { explícito no texto da contextualização. }\end{array}$ \\
\hline Detalhamento & $\begin{array}{l}\text { Detalhar, com o uso de imagens, a forma como os alunos deverão } \\
\text { manipular a tecnologia digital escolhida. Ressalta-se que maior } \\
\text { riqueza de detalhes tende a facilitar a compreensão por parte dos } \\
\text { estudantes. }\end{array}$ \\
\hline Referências & $\begin{array}{l}\text { Apresentar as atividades a serem desenvolvidas pelos alunos, } \\
\text { com base na tecnologia digital utilizada. }\end{array}$ \\
\hline $\begin{array}{l}\text { Apresentar as referências do trabalho, conforme as normas } \\
\text { estudadas na disciplina de Metodologia Científica. }\end{array}$ \\
\hline
\end{tabular}

Fonte: Elaboração própria (2020).

Nos encontros 8 e 9, nos quais os projetos educacionais foram construídos pelos futuros docentes em computação, foram também identificadas as maiores apreensões e dificuldades dos alunos, sendo a percepção inicial referente à dificuldade de escrita por parte dos discentes, que realizavam questionamentos como:

Aluno05 - Professor, tem como o senhor ler e falar se tá bom?

Aluno01 - Professor, é assim que se faz uma contextualização?

Aluno08 - Professor, leia aqui e me diz o que você acha. 
Há de se ressaltar que a maioria dos alunos estavam no $3^{\circ}$ período do curso e que muitos só tiveram contato com textos científicos na disciplina de Metodologia Científica do $2^{\circ}$ período. Com isso, pode-se evidenciar a dificuldade apresentada.

Outra percepção dos encontros 8 e 9 foi o desafio de os alunos vivenciarem o planejamento de práticas pedagógicas com a visão de docentes. Tal constatação foi identificada quando expuseram questionamentos como:

Aluno02 - Estamos conversando aqui e acho que precisamos montar o projeto na visão do aluno, não é Professor?

Aluno13 - Professor, só detalhar o GeoGebra tá certo?

Aluno03 - Professor, só mostrar uma parte do PhET e pedir para o aluno repetir com as outras funções estaria bom?

Aluno11 - Professor, acho que como nosso projeto é para crianças, temos que descrever para a professora que for usar, certo?

Com os questionamentos, evidenciou-se a necessidade da quebra de paradigma por parte dos licenciandos, uma vez que eles deveriam deixar a visão de estudantes para adotarem a visão pedagógica de um professor. Ademais, os desafios da proposição de novas práticas pedagógicas que possam contribuir para os processos de ensino devem ser rotina na vida acadêmica dos futuros docentes de computação. Tal argumento vai ao encontro da ideia de Silva e Miranda (2005), a qual discorre que é na formação inicial de professores que se faz necessário refletir sobre os efeitos a se atingir com as tecnologias digitais, levando-se em consideração uma série de variáveis a serem organizadas de forma a assegurar uma estratégia eficaz de ensino.

Finalizando os encontros, o de número 10 foi exclusivamente para a apresentação dos projetos educacionais desenvolvidos pelos licenciandos em computação. Nesse contexto, o projeto educacional desenvolvido pelo Grupo 1, intitulado "Ambiente de aprendizagem sobre teorias educacionais e a docência utilizando a Wiki", objetivou auxiliar os processos de ensino do conteúdo de Tendências Pedagógicas da disciplina de Didática do Curso Superior de Licenciatura em Computação, por meio do uso da ferramenta colaborativa wiki. Para tanto, a estrutura do projeto é apresentada na Figura 4.

Figura 4 - Projeto Educacional do Grupo 1

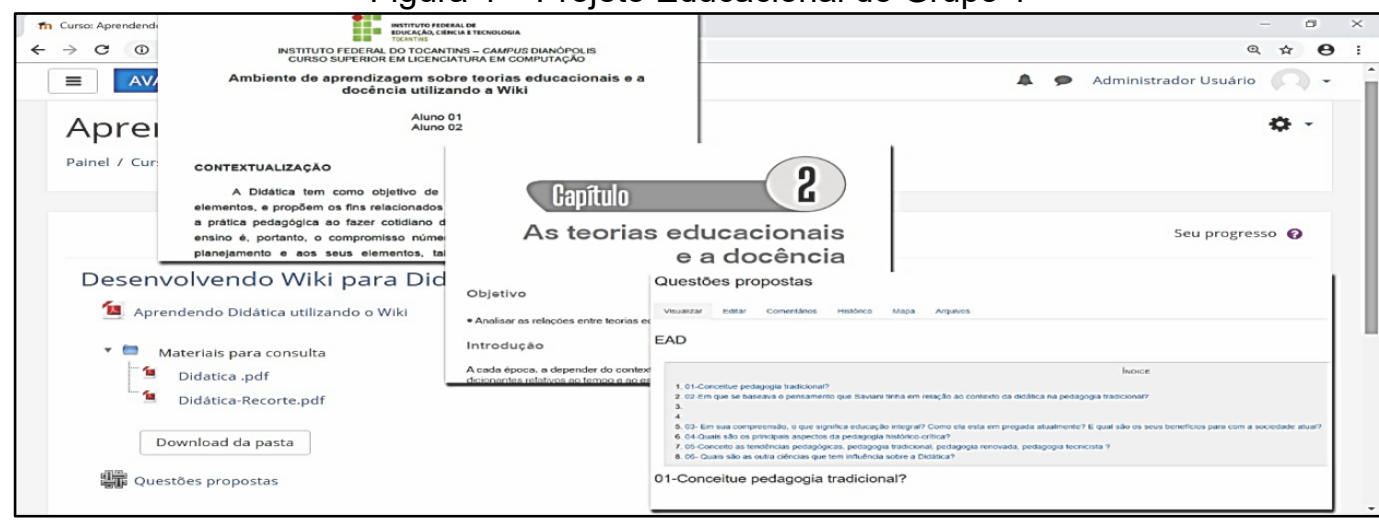

Fonte: Elaboração própria (2020), a partir da plataforma Moodle.

Com base na Figura 4, a produção disponibilizou acesso ao documento base com o detalhamento sobre o projeto educacional que serviria como guia para o desenvolvimento das atividades propostas. Além disso, também foram disponibilizados materiais de consulta (recortes de livros sobre o assunto) que

4


serviriam para edição do wiki, que seria construído com as respostas das perguntas propostas. Dando seguimento às apresentações, o Grupo 2 expôs seu projeto educacional intitulado "Balões e eletricidade estática por meio de recursos tecnológicos", o qual objetivou trabalhar o conteúdo de Eletricidade Estática, da disciplina de Química, para turmas de $1^{\circ}$ ano do Ensino Médio, utilizando um simulador do PhET, denominado Balões e Eletricidade Estática, como mostra a Figura 5.

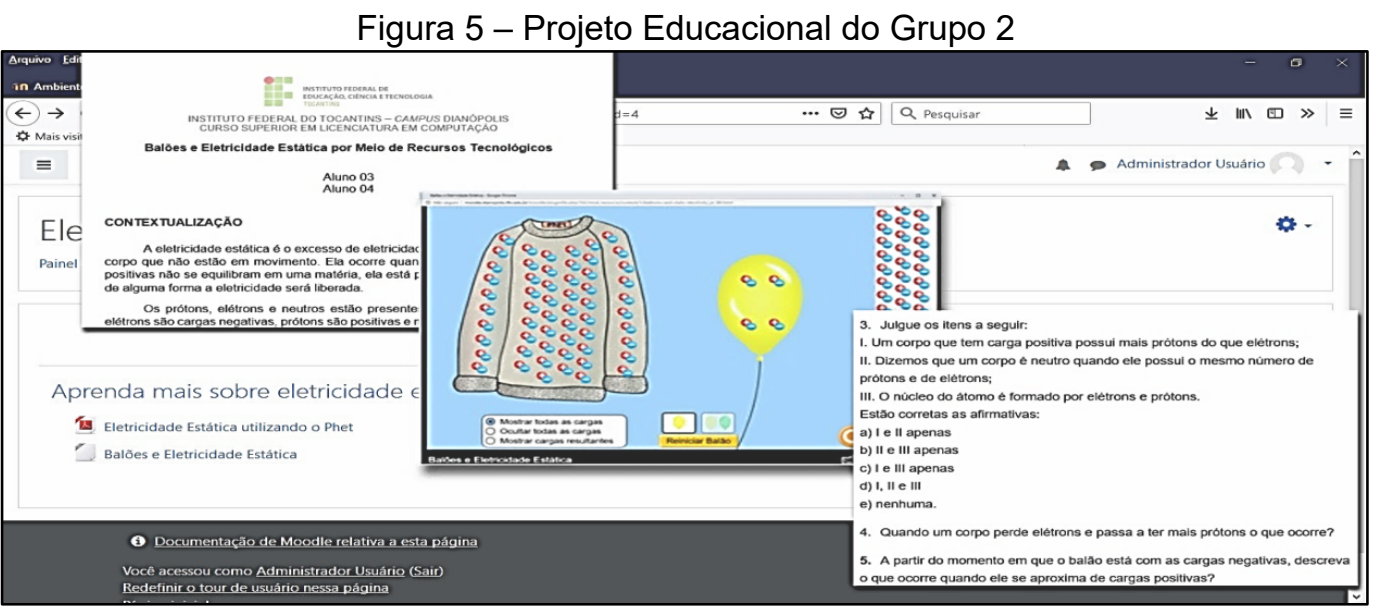

Fonte: Elaboração própria (2020), a partir da plataforma Moodle.

Na Figura 5, é possível verificar que o trabalho foi organizado com dois links, o primeiro referente ao documento base, que abarcava uma contextualização do assunto, o detalhamento do uso da ferramenta e as atividades propostas. $\mathrm{O}$ segundo link disponibilizou o simulador de química para realização de download.

O trabalho apresentado em sequência foi do Grupo 3, o qual foi intitulado "Uso do GeoGebra na Plataforma do AVA". O projeto educacional em questão, que pode ser visto na Figura 6, objetivou auxiliar, por meio do uso do GeoGebra, os processos de ensino do conteúdo de matriz, da disciplina de Matemática, para alunos do $9^{\circ}$ ano do Ensino Fundamental.

Figura 6 - Projeto Educacional do Grupo 3

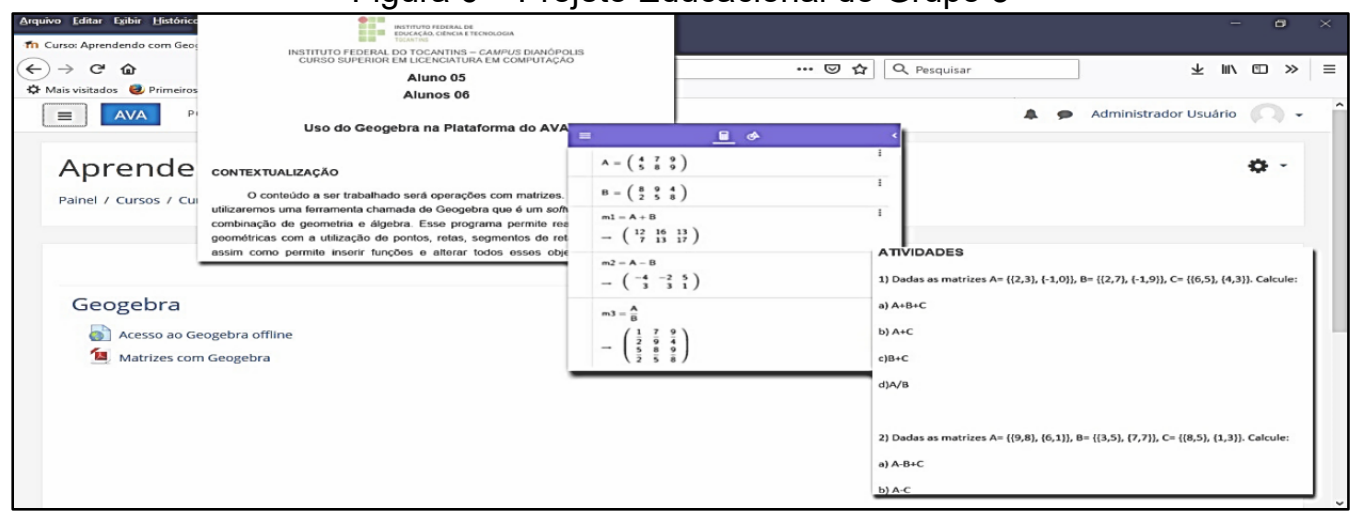

Fonte: Elaboração própria (2020), a partir da plataforma Moodle.

Assim como mostrado na Figura 6, o projeto foi organizado com links para acessar o documento base e o GeoGebra na versão offline. Nesse sentido, no documento base foram descritos a contextualização, o detalhamento de uso do GeoGebra e as atividades propostas.

Em seguida, foi a vez do Grupo 4 apresentar seu projeto educacional, o qual teve 
como título "Minicurso de Eletrônica", como mostra a Figura 7. Como pode ser percebido pelo título, tal projeto teve o objetivo de auxiliar o ensino de Eletrônica Básica em um minicurso destinado aos alunos do Ensino Médio Técnico em Informática, por meio do uso da ferramenta Fritzing.

Figura 7 - Projeto Educacional do Grupo 4

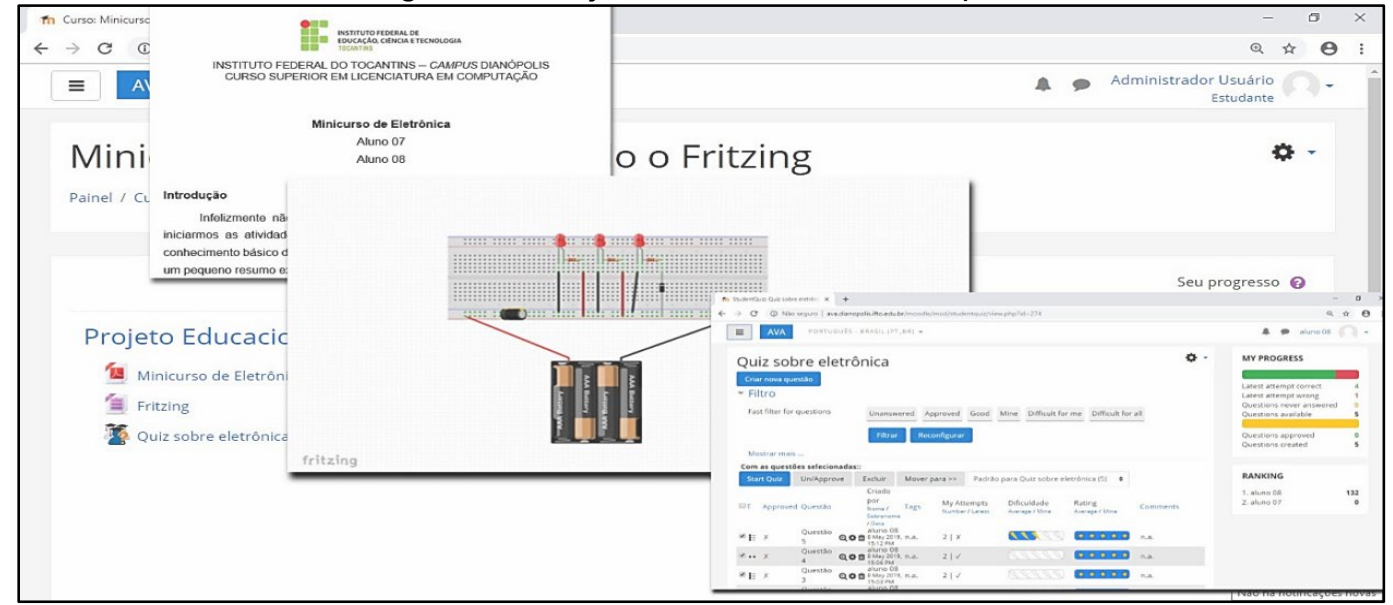

Fonte: Elaboração própria (2020), a partir da plataforma Moodle.

Como notado na Figura 7, o trabalho foi organizado com o documento base, que descrevia as informações que o aluno precisaria para desenvolver as atividades propostas, o link para download da ferramenta Fritzing e um Quiz utilizando o StudentQuiz com as atividades do minicurso.

Dando continuidade à apresentação dos projetos educacionais, o Grupo 5 apresentou seu trabalho intitulado "Aprendendo Geometria através do Software GeoGebra", como mostra a Figura 8, que objetivou o ensino do conteúdo de Polígonos Regulares com auxílio do GeoGebra para alunos do $9^{\circ}$ ano do Ensino Fundamental.

Figura 8 - Projeto Educacional do Grupo 5

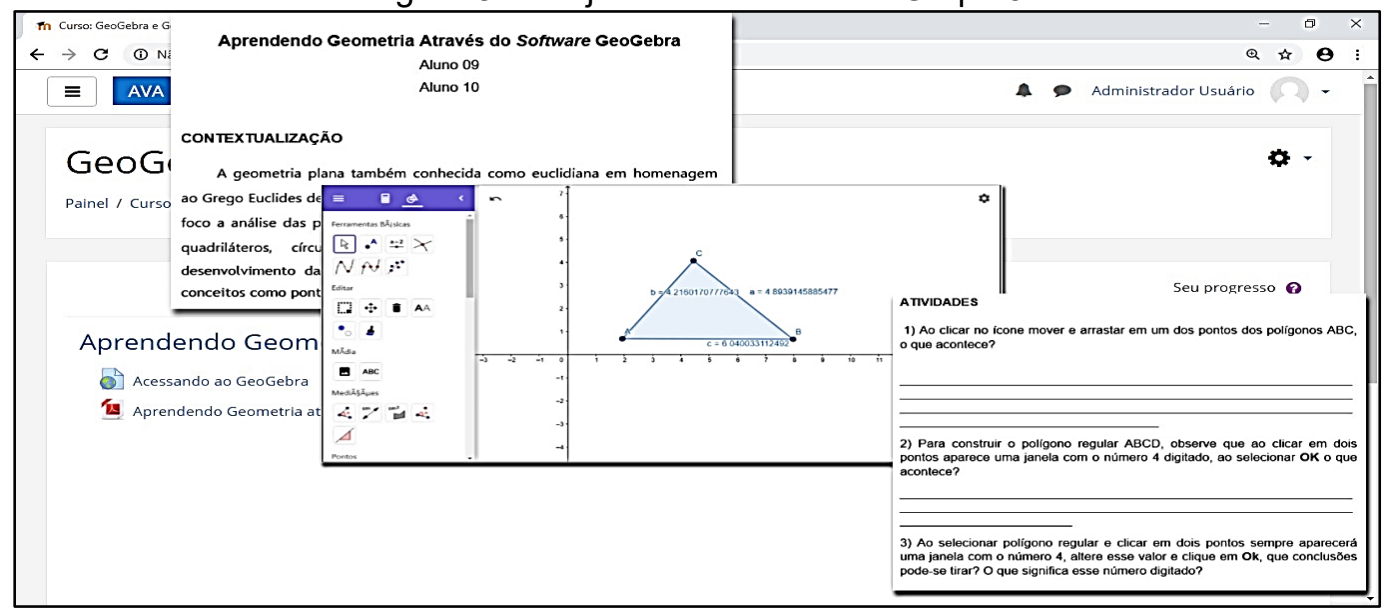

Fonte: Elaboração própria (2020), a partir da plataforma Moodle.

Percebe-se na Figura 8 que o Grupo 5 organizou o projeto com os links para acessar o documento base e o GeoGebra na versão offline, sendo no documento base descritos a contextualização, os detalhes de uso da ferramenta e as atividades propostas.

O Grupo 6 foi o seguinte a realizar exposição do seu projeto, o qual teve como título 
"Educação Infantil com o GeoGebra", como mostra a Figura 9. Diante disso, a produção objetivou ensinar a construção de palavras por meio da junção de vogais e consoantes para alunos da Educação Infantil.

Figura 9 - Projeto Educacional do Grupo 6

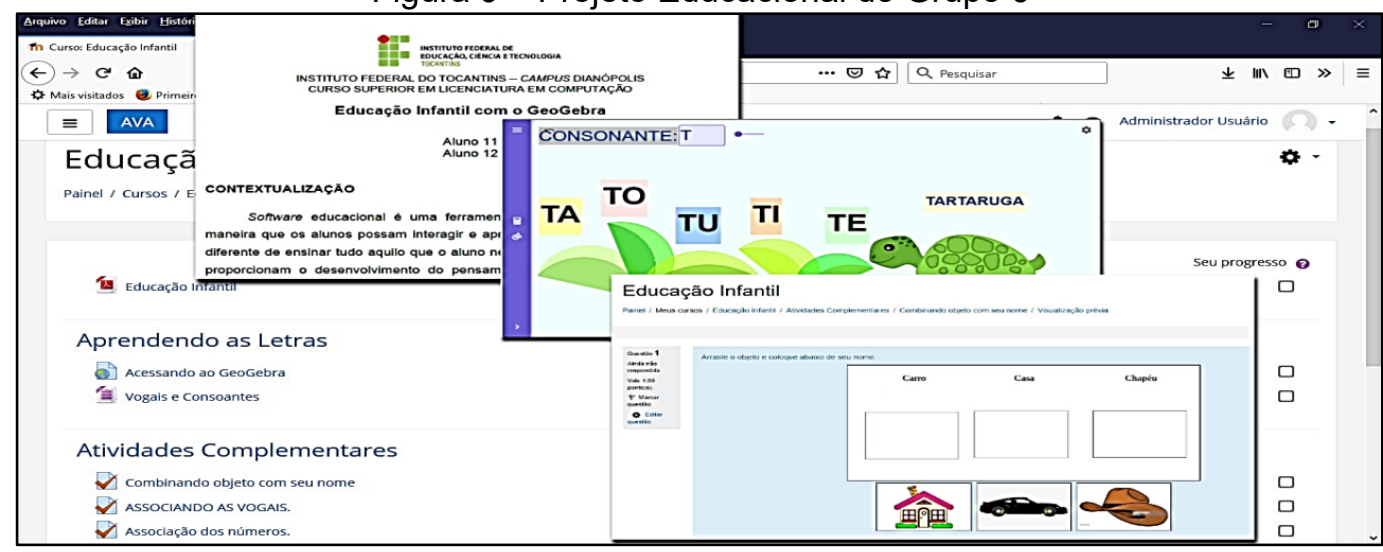

Fonte: Elaboração própria (2020), a partir da plataforma Moodle.

Durante sua apresentação, o Grupo 6 enfatizou que o projeto em questão foi desenvolvido pensando em professores do Ensino Infantil. No entanto, outra ressalva realizada pelos integrantes do grupo foi que faltam trabalhos que relacionassem o uso de tecnologias digitais com a temática escolhida e que para nortear sua produção utilizaram um objeto educacional chamado "Consonanti e vocali", disponível no site da ferramenta GeoGebra. Diante disso, organizaram seu trabalho com o documento base, detalhando todo o funcionamento, o link para acessar o GeoGebra offline, o objeto educacional a ser utilizado no GeoGebra e as atividades de arrastar e soltar imagens.

Seguindo com as apresentações, o Grupo 7 expôs seu trabalho intitulado "Utilização do GeoGebra nas atividades de Descobrimento de Máscaras de Sub-rede", o qual pode ser analisado na Figura 10 e que teve por objetivo o uso de objetos educacionais desenvolvidos para o GeoGebra, para a conversão de Base 2 (binária) para Base 10 (decimal) e vice-versa, com o intuito de auxiliar o ensino do conteúdo referente a Máscaras de Redes de Computadores, para alunos do $2^{\circ}$ ano do Ensino Médio Técnico em Informática. Assim sendo, foram utilizados objetos educacionais, disponibilizados no site do GeoGebra, nomeados como "Binário" - que realizava a conversão de Base 10 para Base 2 -, e "Sistema de numeração binário" - que realizava a conversão de Base 2 para Base 10.

Figura 10 - Projeto Educacional do Grupo 7

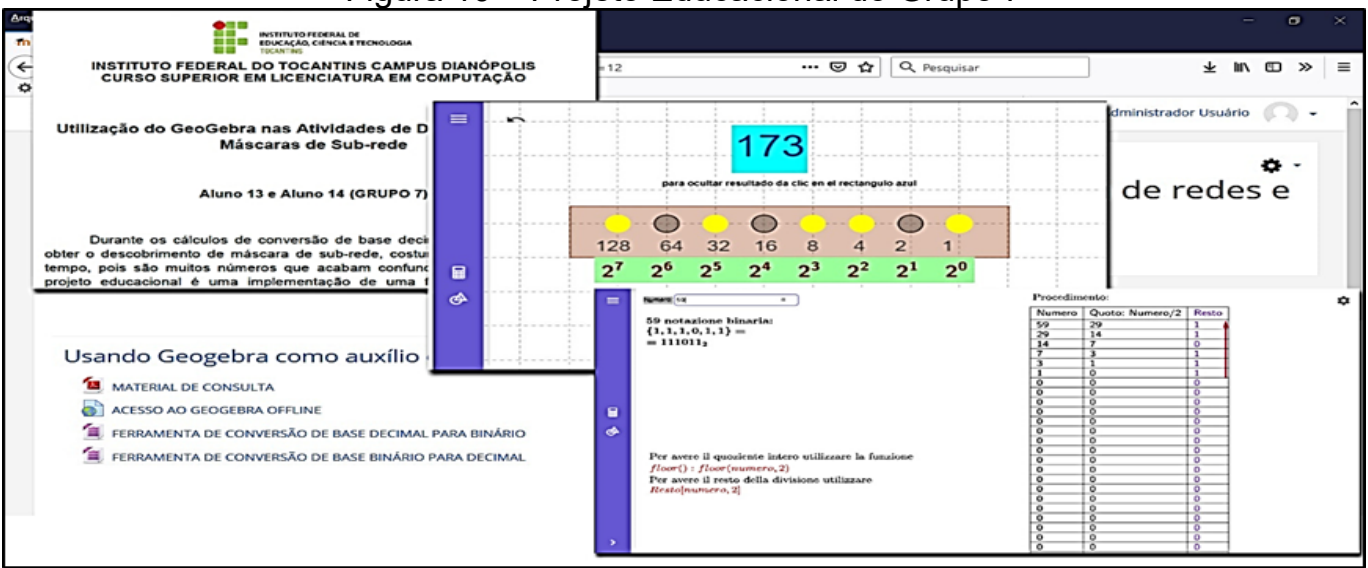

Fonte: Elaboração própria (2020), a partir da plataforma Moodle. 
Como pode ser notado na Figura 10, o projeto educacional do Grupo 7 foi organizado com o documento base, contendo o detalhamento de todo trabalho, 0 link para o GeoGebra offline e os objetos de aprendizagem a serem utilizados no GeoGebra.

Para finalizar as apresentações dos projetos educacionais, o Grupo 8 apresentou seu trabalho, intitulado "Cibernética Introdução à Informática", que pode ser visto na Figura 11. A produção em questão objetivou o ensino do conteúdo de Sistemas Informatizados, da disciplina de Introdução à Informática do $1^{\circ}$ ano do ensino médio técnico, por meio de um jogo digital, o qual foi concebido pelos próprios licenciandos em computação.

Figura 11 - Projeto Educacional do Grupo 8

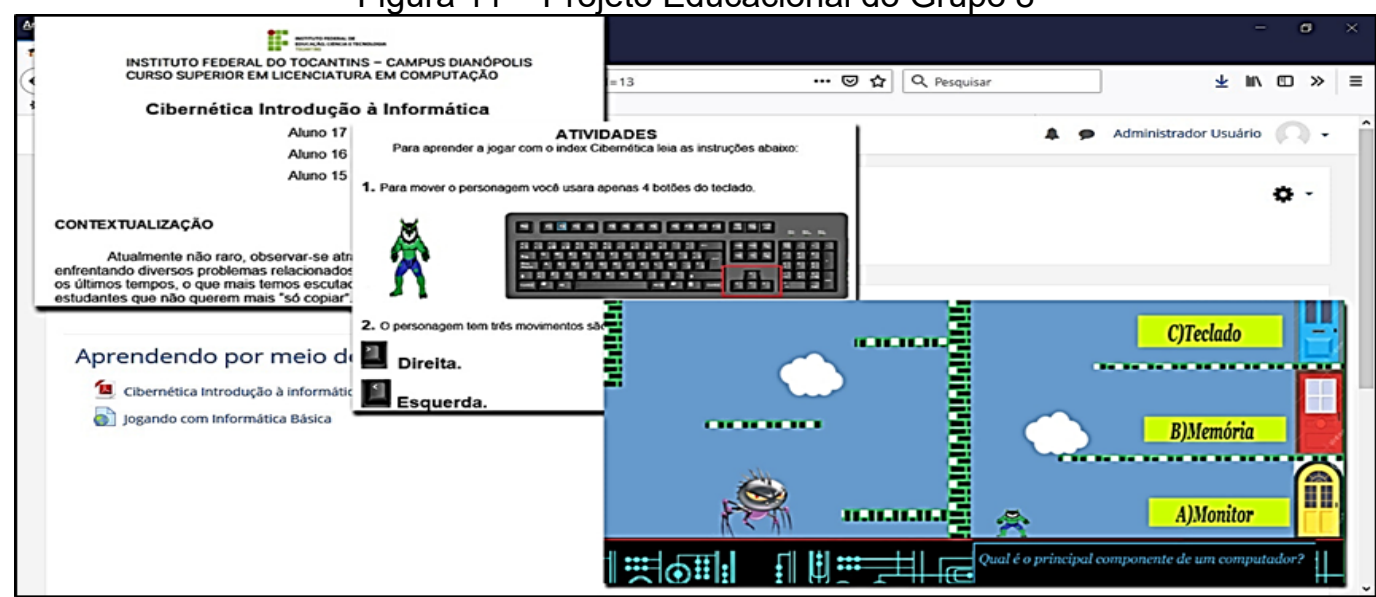

Fonte: Elaboração própria (2020), a partir da plataforma Moodle.

Com a apresentação do projeto educacional do Grupo 8 percebeu-se que, mesmo não utilizando as ferramentas apresentadas nos encontros iniciais, a inspiração para a criação do jogo digital se deu pela utilização dos simuladores do PhET no encontro 5 e do StudentQuiz utilizado no encontro 6. Dessa forma, o grupo estruturou sua produção com o documento base, onde estavam presentes as informações sobre o conteúdo a ser trabalho e o jogo desenvolvido, bem como o link para acessar o jogo digital.

\section{Percepções sobre os Projetos Educacionais}

Durante o desenvolvimento dos projetos educacionais, foi possível perceber as principais dificuldades encontradas pelos futuros docentes em computação. No primeiro momento, a principal dificuldade apresentada pelos licenciandos foi a falta de experiência na produção de textos acadêmicos, o que levou a maioria dos alunos a terem insegurança na construção do documento que traria a especificação de todo o projeto.

A segunda dificuldade demonstrada, foi na manipulação do Ambiente Virtual de Aprendizagem e nas demais tecnologias digitais utilizadas. Isso se deu pelo fato de os alunos terem contato pela primeira vez com esses tipos de recursos na intervenção proposta.

Outra dificuldade percebida foi a falta de experiência na concepção de práticas pedagógicas na visão de professor, pois a maioria da turma não havia sido desafiada, até então, a vivenciar os processos de ensino pelos quais um docente

(10)


deve ser submetido.

Há de se ressaltar ser compreensível que as dificuldades supracitadas se manifestassem, uma vez que a intervenção ocorreu em uma disciplina do $3^{\circ}$ período do curso de Licenciatura em Computação. Todavia, com o desenvolvimento dos projetos educacionais foi possível visualizar o potencial dos alunos na proposição de novas alternativas aos processos de ensino.

O empenho e interesse em conciliar de forma satisfatória o assunto a ser trabalhado com uma ferramenta digital, trouxe novos pilares para a vivência acadêmica e profissional dos licenciandos, sem citar que os trabalhos produzidos possuem relação com vários níveis de formação, que vão desde a Educação Infantil até o Ensino Superior.

\section{Considerações finais}

Com o desenvolvimento dos encontros, foi possível perceber inicialmente, por meio do método de observação, que os alunos não possuíam conhecimentos e familiaridade na manipulação de tecnologias digitais voltadas para o ensino. Ressalta-se que para a maioria da turma foi a primeira vez em que teve contato com um AVA, especialmente uma oportunidade em que não tivesse interação com a Internet.

Com o decorrer dos encontros, verificou-se que a estrutura preparada no AVA Moodle foi motivadora e propiciou interesse aos alunos. Em boa parte dos encontros, por meio do método de observação, notou-se nos diálogos o desejo da maioria dos estudantes em cumprir com êxito cada etapa proposta. Diante disso, foi possível compreender que todo o esforço na preparação da intervenção foi satisfatório, à medida que a metodologia se aproximou da linguagem dos participantes.

Desse modo, a produção dos projetos educacionais trouxe benefícios à vida acadêmica dos licenciandos em computação, o que se acredita poderá refletir no seu futuro como docente, pois o desafio de vivenciar o planejamento pedagógico de um professor foi uma quebra de paradigma para boa parte dos estudantes. Assim, espera-se que o desenvolvimento de novas práticas envolvendo recursos digitais se torne uma constante atividade na vida desses licenciandos, para que, dessa forma, sejam capazes de compartilhar os conhecimentos adquiridos com seus futuros alunos.

Por fim, como sugestões para futuros trabalhos, pretende-se aplicar a proposta apresentada neste artigo em outras disciplinas do curso de Licenciatura em Computação. Além disso, devido às dificuldades de comunicação com a Internet, já citadas, do campus Dianópolis do IFTO, deseja-se organizar um curso de extensão com a presente temática, no entanto, focando na formação continuada dos docentes.

\section{Referências}

ALMEIDA, Maria Elizabeth Bianconcini de. Educação a distância na internet: abordagens e contribuições dos ambientes digitais de aprendizagem. Educação e 
Pesquisa, São Paulo, v. 29, n. 2, p. 327-340, 2003. Disponível em: https://www.scielo.br/pdf/ep/v29n2/a10v29n2.pdf. Acesso em: 3 jul. 2020.

ALMEIDA, Maria Elizabeth Bianconcini de. Prática e formação de professores na integração de mídias. Prática pedagógica e formação de professores com projetos: articulação entre conhecimentos, tecnologias e mídias. In: ALMEIDA, Maria Elizabeth Bianconcini de.; MORAN, José Manuel (org.). Integração das tecnologias na educação. Brasília, DF: Ministério da Educação/SEED/TV Escola/Salto para o Futuro, 2005, p. 38-45. Disponível em: http://portal.mec.gov.br/seed/arquivos/pdf/iniciaissf.pdf. Acesso em: 3 jul. 2020.

ALVES, Lynn Rosalina Gama; MINHO, Marcelle Rose da Silva; DINIZ, Marcelo Vera Cruz. Gamificação: diálogos com a educação. In: FADEL, Luciane Maria; ULBRICHT, Vânia Ribas; BATISTA, Cláudia; VANZIN, Tarcísio (org.). Gamificação na Educação. São Paulo: Pimenta Cultural, 2014, p. 74-97. Disponível em: https://www.pimentacultural.com/gamificacao-na-educacao. Acesso em: 3 jul. 2020.

COUTINHO, Mariana de Souza; FARBIARZ, Alexandre. Redes sociais e educação: uma visão sobre os nativos e imigrantes digitais e o uso de sites colaborativos em processos pedagógicos. In: SIMPÓSIO HIPERTEXTO E TECNOLOGIAS DA EDUCAÇÃO, 3., 2010, Recife, PE. Anais eletrônicos [...], 2010, p.1-9. Disponível em: $\quad$ http://www.nehte.com.br/simposio/anais/Anais-Hipertexto-2010/MarianaSouza-Coutinho\&Alexandre\%20Farbiarz.pdf. Acesso em: 3 jul. 2020.

KENSKI, Vani Moreira. Tecnologias e tempo docente. Campinas, SP: Papirus, 2013.

LIMA, Patricia Rosa Traple. Novas tecnologias da informação e comunicação na educação e a formação dos professores nos cursos de licenciatura do Estado de Santa Catarina. 2001. Dissertação (Mestrado em Ciência da Computação) - Universidade Federal de Santa Catarina - Florianópolis, SC, 2001. Disponível em: https://repositorio.ufsc.br/ xmlui/handle/123456789/80007. Acesso em: 3 jul. 2020.

LÜDKE, Menga; ANDRÉ, Marli E. D. A. Pesquisa em educação: abordagens qualitativas. 2. ed. Rio de Janeiro: Editora Pedagógica e Universitária, 2013.

MENEZES, Douglas Carvalho de. Desenvolvimento da cultura digital na formação inicial do professor de matemática. 2014. 191 f. Dissertação (Mestrado em Educação) - Universidade Federal de Uberlândia, Minas Gerais, 2014. Disponível em: https://repositorio.ufu.br/bitstream/123456789/13962/1/ DesenvolvimentoCulturaDigital.pdf. Acesso em: 3 jul. 2020.

MORAN, José Manuel. Integrar as tecnologias de forma inovadora. In: MORAN, José Manuel; MASETTO, Marcos T.; BEHRENS, Marilda Aparecida. Novas tecnologias e mediação pedagógica. 21. ed. rev. e atual. Campinas, SP: Papirus, 2013. p. 36-46.

MORAN, José Manuel; MASETTO, Marcos T; BEHRENS, Marilda Aparecida. Novas tecnologias e mediação pedagógica. Campinas, SP: Papirus, 2015.

MUNHOZ, Antonio Siemsen. $O$ estudo em ambiente virtual de aprendizagem: um guia prático. Curitiba: InterSaberes, 2013.

PADILHA, Teresinha Aparecida Faccio; BRANCHIER, Henrique Scalcon. A trigonometria no triângulo retângulo por meio de recursos tecnológicos. In:

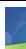


DULLIUS, Maria Madalena; QUARTIERI, Marli Teresinha (org.). Aproximando a Matemática e a Física por meio de recursos tecnológicos: Ensino Médio. 1. ed. Lajeado, RS: Univates, 2016. p. 27-50. Disponível em: https://www.univates.br/editora-univates/media/publicacoes/191/pdf_191.pdf.

Acesso em: 24 set. 2019.

PERRENOUD, Philippe et al. Formando professores profissionais: três conjuntos de questões. In: PERRENOUD, Philippe et al. Formando professores profissionais: Quais estratégias? Quais as competências. Porto Alegre: Artmed, 2008. p. 11-22.

PONTE, João Pedro da. As TIC no início da escolaridade: perspectivas para a formação inicial de professores. In: PONTE, João Pedro da. (org.). A formação para a integração das TIC na educação pré-escolar e no $1 .^{\circ}$ ciclo do ensino básico. Porto: Porto Editora, 2002. p. 19-26. (Cadernos de Formação de Professores, $\quad$ n. 4 ). Disponível em: https://repositorio.ul.pt/bitstream/10451/4202/1/02-Ponte\%20\%28TIC-

INAFOP\%29.pdf. Acesso em: 3 jul. 2020.

PRENSKY, Marc. Nativos digitais, imigrantes digitais. On the horizon, Lincoln, v. 9. n. 5, p. 1-6, 2001. Disponível em: https://www.marcprensky.com/writing/ Prensky\%20-\%20Digital\%20Natives,\%20Digital\%20Immigrants\%20-\%20Part1.pdf. Acesso em: 3 jul. 2020.

QUARTIERI, Marli Teresinha; NEVES, Fernanda; WEIMER, Rafael Diogo. Atividades elaboradas por professores participantes de um curso de formação com foco no uso de recursos tecnológicos. In: DULLIUS, Maria Madalena; QUARTIERI, Marli Teresinha (org.). Aproximando a Matemática e a Física por meio de recursos tecnológicos: Ensino Médio. 1. ed. Lajeado, RS: Univates, 2016. p. 97115. Disponível em: https://www.univates.br/editoraunivates/media/publicacoes/191/pdf_191.pdf. Acesso em: 24 set. 2019.

REIS, Valdeci; MENDES, Geovana Mendonça Lunardi. De iniciantes a vanguardistas: o uso de tecnologias digitais por jovens professores. Revista HOLOS, Natal, RN, v. 1, p. 297-316, 2018. DOI: https://doi.org/10.15628/holos. 2018.4867. Disponível em: http://www2.ifrn.edu.br/ojs/index.php/HOLOS/ article/view/4867. Acesso em: 3 jul. 2020.

SILVA, Fátima; MIRANDA, Guilhermina Lobato. Formação inicial de professores e tecnologias. In: CANDIDO, Paulo Dias; FREITAS, Varela (org.). CONFERÊNCIA INTERNACIONAL EM TECNOLOGIAS DE INFORMAÇÃO E COMUNICAÇÃO NA EDUCAÇÃO, 4., 2005, Braga, Portugal. Anais [...]. Braga, Portugal: Centro de Competências Nónio Séc. XXI da Universidade do Minho, 2005. p. 592-606. Disponível em: https://www.nonio.uminho.pt/challenges/ download/atas-challenges2005/. Acesso em: 3 jul. 2020.

STAKE, Robert E. Pesquisa qualitativa: estudando como as coisas funcionam. Tradução: Karla Reis. Porto Alegre, RS: Penso Editora, 2011.

TEIXEIRA, Lucicleide Carlos; STROHSCHOEN, Andreia Aparecida Guimarães. Ambiente virtual de aprendizagem (WIKI) no ensino de genética no Ensino Médio. Programa de Pós-Graduação em Ensino de Ciências Exatas - Univates. 2015. Disponível em: https://www.univates.br/ppgece/media/pdf/ 2015/ambiente_virtual_de_aprendizagem_wiki_no_ensino_de_genetica_no_ensi no_medio.pdf. Acesso em: 24 set. 2019. 
VALENTE, José Armando. Pesquisa, comunicação e aprendizagem com o computador. In: ALMEIDA, Maria Elizabeth Bianconcini de.; MORAN, José Manuel (org.). Integração das tecnologias na educação. Brasília, DF: Ministério da Educação/SEED/TV Escola/Salto para o Futuro, 2005, p.22-31.

VIANNA, Ysmar et al. Gamification, Inc: recreating companies through games. Tradução: Gláucia Machado. 1. ed. Rio de Janeiro: MJV Tecnologia, 2014.

Recebido: 28/10/19

Aprovado: $17 / 08 / 20$

Como citar: NUNES, R. M.; MARCHI, M. I. Desenvolvimento de projetos educacionais por futuros docentes de computação por meio de um AVA offline. Revista de Estudos e Pesquisas sobre Ensino Tecnológico (EDUCITEC), v. 6, e094820, 2020.

Direito autoral: Este artigo está licenciado sob os termos da Licença Creative CommonsAtribuição 4.0 Internacional. 